(2) Open Access Full Text Article

ORIGINAL RESEARCH

\title{
Association Between Blood Eosinophils and Mortality in Critically III Patients with Acute Exacerbation of Chronic Obstructive Pulmonary Disease: A Retrospective Cohort Study
}

This article was published in the following Dove Press journal:

International Journal of Chronic Obstructive Pulmonary Disease

Jia Yang'

Junchao Yang ${ }^{2}$

'The First Clinical College, Zhejiang Chinese Medical University, Hangzhou, People's Republic of China; ${ }^{2}$ Department of Pulmonary and Critical Care Medicine, The First Affiliated Hospital of Zhejiang Chinese Medical University, Hangzhou, People's Republic of China
Correspondence: Junchao Yang Department of Pulmonary and Critical Care Medicine, The First Affiliated Hospital of Zhejiang Chinese Medical University, 54 Youdian Road, Shangcheng District, Hangzhou City, Zhejiang

Province, People's Republic of China Tel +86-13858036093

Email yangjunchaozj@zcmu.edu.cn
Purpose: To explore the relationship between the blood eosinophil concentrations in the early stage and mortality in critically ill patients with acute exacerbation of chronic obstructive pulmonary disease.

Methods: Patient data were extracted from the MIMIC-III V1.4 database. Only the acute exacerbation of chronic obstructive pulmonary disease patients with the first measurement time of blood eosinophil concentrations (\%) between 24 hours before admission and 24 hours after admission was included. The logistic regression model was used to analyze the association between eosinophil and outcomes.

Results: 1019 patients were included in the study. Two multivariate regression models were built. The adjusted odds ratio of in-hospital mortality, in-ICU mortality, hospital length of stay and ICU length of stay for initial blood eosinophil concentrations in model 1 (adjusted for SAPS II, cardiac arrhythmias, solid tumor, metastatic cancer, liver disease, neutrophils) were 0.792 (95\% CI: 0.643-0.976, p=0.028), 0.812 (95\% CI: 0.645-1.022, p=0.076), 0.847 (95\% CI: $0.772-0.930, \mathrm{p}=0.001)$ and 0.914 (95\% CI: $0.836-1.000, \mathrm{p}=0.049)$ respectively. Meanwhile, in model 2 (adjusted for SOFA score, age, cardiac arrhythmias, solid tumor, metastatic cancer, liver disease, neutrophils) ORs were 0.785 (95\% CI: 0.636-0.968, $\mathrm{p}=0.024), 0.807$ (95\% CI: 0.641-1.016, p=0.068), 0.854 (95\% CI: $0.778-0.939, \mathrm{p}=0.001)$ and 0.917 (95\% CI: $0.838-1.004, \mathrm{p}=0.060)$ respectively. The area under the ROC curve for eosinophil initial was 0.608 (95\% CI: $0.559-0.657)$. The discriminatory eosinophil thresholds were $0.35 \%$ (sensitivity $=0.59$, specificity $=0.61$ ) for in-hospital mortality.

Conclusion: Increased blood eosinophils were associated with decreased in-hospital mortality and shorten hospital length of stay in critically ill patients with acute exacerbation of chronic obstructive pulmonary disease. A discriminatory eosinophil threshold of $0.35 \%$ for mortality was found, but further studies were needed to verify it.

Keywords: chronic obstructive pulmonary disease, exacerbation, eosinophil, mortality, critical care

\section{Introduction}

Eosinophil seems to be considered as an important biomarker in guiding treatments and reflecting prognosis in patients with chronic obstructive pulmonary disease (COPD) recently. Although sputum eosinophil concentrations have been proved as a better biomarker, ${ }^{1}$ only very few medical organizations carry out it, which affects its clinical value. However, blood eosinophil has also been confirmed that it might 
predict exacerbation risk, ${ }^{2,3}$ predict ICS treatment response, and guide medication ${ }^{4-7}$ in some studies. Moreover, some researches aimed at patients with acute exacerbation of chronic obstructive pulmonary disease (AECOPD) also indicated that blood eosinophil had an association with outcomes ${ }^{8-10}$ and served as a reference for the use of antibiotics ${ }^{11}$ and corticosteroids. ${ }^{12}$ However, there are very limited studies on exploring the role of blood eosinophil in critically ill patients with AECOPD.

Therefore, this study aims to explore the relationship between blood eosinophil concentrations in the early stage and mortality in critically ill patients with AECOPD.

\section{Method}

\section{Data Source}

All data in the study were extracted from the Medical Information Mart for Intensive Care III (MIMIC-III v1.4) database, ${ }^{13}$ which comprises 61,532 stays for adult and neonatal patients in ICU at the Beth Israel Deaconess Medical Center in Boston from June 2001 to October 2012. The establishment of the database was approved by the Institutional Review Boards of the Massachusetts Institute of Technology and Beth Israel Deaconess Medical Center. To get access to the MIMICIII database, Jia Yang completed the online course and passed the "Protecting Human Research Participants Exam" of the National Institutes of Health (Record ID: 34,619,217). This study was approved by ethics committee of the First Affiliated Hospital of Zhejiang Chinese Medicial University [2020-KL-154-01].

\section{Study Population and Definitions}

The information of all patients with AECOPD was extracted from the MIMIC-III database. AECOPD was defined as an acute worsening of respiratory symptoms that results in additional therapy. ${ }^{14}$ The patients who lacked basic information and the data of blood eosinophil concentrations were excluded. Because the aim of this study was to explore the relationship between the value of blood eosinophil concentrations in the early stage of acute exacerbation, only the patients with measurement time between 24 hours before admission and 24 hours after admission were included. Blood eosinophil concentrations (\%) were used in this study. Eosinophil initial $_{\text {was }}$ defined as the first value of blood eosinophil concentrations measured in the stage between 24 hours before admission and 24 hours after admission. The definition of eosinophil max was the maximum value during the hospitalization. Eosinophil mean was defined as the arithmetic mean of all values during hospitalization.

\section{Outcomes}

The primary outcome was in-hospital mortality. The secondary outcomes included in-ICU mortality, hospital length of stay (LOS), and ICU length of stay (LOS). Inhospital mortality and in-ICU mortality were defined as death during hospitalization and ICU, respectively. The hospital LOS and the ICU LOS were stratified into two levels, respectively, based on medians: hospital LOS level 1 ( $\leq 7$ days) and level 2 (>7 days); ICU LOS level $1(\leq 3$ days) and level 2 (>3days).

\section{Statistics}

Continuous variables were presented as the mean with standard deviation (SD) or median with interquartile ranges and compared using Student's test or rank-sum test. The categorical variables were presented as a percentage and compared using the $\chi^{2}$ test. The logistic regression models were built to explore the relationship between eosinophil and outcomes. The variables were chosen according to univariate analysis and clinical experience. Two multivariate models were used. In model 1, variables were adjusted for SAPS II score, cardiac arrhythmias, solid tumor, metastatic cancer, liver disease, neutrophils (\%). Meanwhile, in model 2, variables were adjusted for SOFA score, age, cardiac arrhythmias, solid tumor, metastatic cancer, liver disease, neutrophils $(\%)$. The linear regression models were built to perform collinearity diagnosis to verify the correlation between variables. The receiver operating characteristic (ROC) curve test was performed to measure the sensitivity and specificity of eosinophil and calculated the area under the curve to ascertain the quality of eosinophil as a predictor of in-hospital mortality. The discriminatory thresholds were confirmed as the values when the sensitivity (1-specificity) was maximum. All tests were two-sided, and $\mathrm{p}<$ 0.05 was considered statistically significant. Statistical analyses were performed with SPSS 25.0 software.

\section{Results}

1198 patients with AECOPD were identified from the MIMIC-III database, and 1019 patients were included eventually after some exclusion criteria (Figure 1). The demographic characteristics of the included patients are 


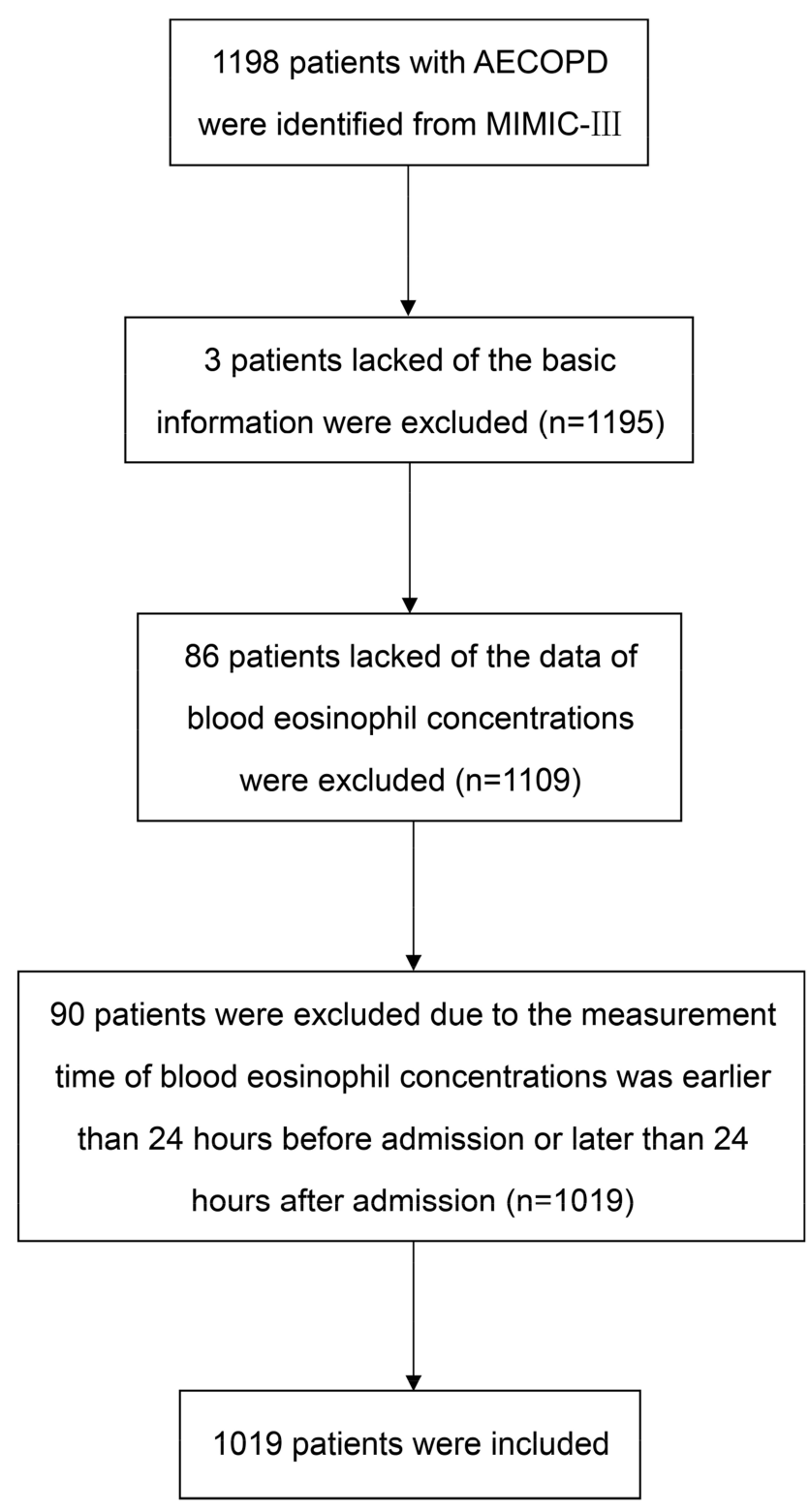

Figure I Flowchart of patient selection.

presented in Table 1. All variables of eosinophils were significantly lower for non-survivors than survivors.

The results of univariate and multivariate regression analyses for outcomes are shown in Table 2. Two multivariate models were built. In multivariate model 1, covariates were adjusted for SAPS II, cardiac arrhythmias, solid tumor, metastatic cancer, liver disease, neutrophils (\%). Meanwhile, covariates were adjusted for SOFA score, age, cardiac arrhythmias, solid tumor, metastatic cancer, liver disease, neutrophils (\%) in model 2 . The initial blood eosinophils concentrations were significantly associated with in-hospital mortality and hospital LOS in both models. The adjusted odds ratio (ORs) of in-hospital mortality and hospital LOS for initial eosinophil concentrations in model 1 were 0.792 (95\% CI: $0.643-0.976, \mathrm{p}=0.028)$ and 0.847 (95\% CI: 0.772-0.930, $\mathrm{p}=0.001)$. Meanwhile, in model 2 ORs were 0.785 (95\% CI: $0.636-0.968$, $\mathrm{p}=0.024)$ and 0.854 (95\% CI: 0.778-0.939, $\mathrm{p}=0.001)$.

The ROC curve of in-hospital mortality is shown in Figure 2. The area under the ROC curve for eosinophil $_{\text {initial }}$ was 0.608 (95\% CI: $\left.0.559-0.657\right)$. The discriminatory eosinophil thresholds were $0.35 \%$ (sensitivity $=0.59$, specificity $=0.61$ ) for in-hospital mortality.

\section{Discussion}

Our results showed that increased blood eosinophil concentrations were associated with decreased in-hospital mortality and shorten hospital length of stay in critically ill patients with AECOPD. Besides, the discriminatory thresholds in this study calculated by the ROC curve were $0.35 \%$ for in-hospital mortality.

Three studies had explored the relationship between eosinophil and mortality in critically ill patients with AECOPD before. And the same trend was found in ours. The results from Holland' study ${ }^{15}$ showed that significant differences were seen in mortality (4/23 (17.4\%) vs $1 / 42$ $(2.4 \%), p=0.049)$ in normal eosinophil group and eosinopenia group $(\leq 0.04)$, which indicated that the eosinophil count might be a useful marker of severity inpatients with AECOPD. However, the sample size of this study was small, only 65 patients were included. A prospective study from Rahimi-Rad ${ }^{16}$ that included 100 patients showed that there was a significant relationship existing between eosinopenia and outcomes of patients with AECOPD. The author emphasized to exclude the effect from corticosteroids on eosinophil count, the patients that had received systemic corticosteroids were excluded. Nevertheless, the count of patients receiving corticosteroids was not small, so excluding them would lose a lot of information. We used blood eosinophil concentrations that were measured in the early stage of acute exacerbation (between 24 hours before admission and 24 hours after admission) when the value was less affected by the treatment. The latest study was from Saltürk. ${ }^{17}$ The retrospective study included 647 subjects and the results showed that acute respiratory failure patients with a peripheral eosinophil level $>2 \%$ had a better outcome.

We analyzed the reasons for this phenomenon that eosinophils had an association with mortality as follows. Firstly, there were many phenotypes of AECOPD, and one of them was based on inflammation. ${ }^{18}$ Eosinophilic predominant and 
Table I Comparisons of Demographic Characteristics Between Survivors and Non-Survivors

\begin{tabular}{|c|c|c|c|c|}
\hline Variables & Total $(n=1019)$ & Survivors $(n=887)$ & Non-Survivors $(n=132)$ & $p$ \\
\hline Male & $510(50.0)$ & $443(49.9)$ & $67(50.8)$ & 0.861 \\
\hline Age, yr & $72.4(64.3,80.6)$ & $71.2(63.7,79.7)$ & $79.0(72.3,83.4)$ & $<0.001$ \\
\hline $\begin{array}{l}\text { Ethnicity } \\
\text { White } \\
\text { Black } \\
\text { Hispanic } \\
\text { Asian } \\
\text { Other }\end{array}$ & $\begin{array}{l}776(76.2) \\
141(13.8) \\
23(2.3) \\
16(1.6) \\
63(6.2)\end{array}$ & $\begin{array}{l}669(75.4) \\
132(14.9) \\
22(2.5) \\
12(1.4) \\
52(5.9)\end{array}$ & $\begin{array}{l}107(81.1) \\
9(6.8) \\
1(0.8) \\
4(3.0) \\
11(8.3)\end{array}$ & 0.021 \\
\hline $\begin{array}{l}\text { Admission type } \\
\text { Elective } \\
\text { Emergency } \\
\text { urgent }\end{array}$ & $\begin{array}{l}4(0.4) \\
1004(98.5) \\
11(1.1)\end{array}$ & $\begin{array}{l}4(0.5) \\
873(98.4) \\
10(1.1)\end{array}$ & $\begin{array}{l}0 \\
|3|(99.2) \\
I(0.8)\end{array}$ & 1.000 \\
\hline \multicolumn{5}{|l|}{ Comorbidities } \\
\hline Asthma & $5(0.5)$ & $5(0.6)$ & $0(0)$ & 1.000 \\
\hline \multicolumn{5}{|l|}{ Pneumonia } \\
\hline $\begin{array}{l}\text { Bacterial pneumonia } \\
\text { Viral pneumonia } \\
\text { Pneumonia, unclassified } \\
\text { Ventilator-associated pneumonia } \\
\text { Congestive heart failure } \\
\text { Cardiac arrhythmias } \\
\text { Valvular disease } \\
\text { Pulmonary circulation } \\
\text { Hypertension } \\
\text { Diabetes } \\
\text { Renal failure } \\
\text { Liver disease } \\
\text { Solid tumor } \\
\text { Metastatic cancer } \\
\text { Other neurological }\end{array}$ & $\begin{array}{l}144(14.1) \\
4(0.4) \\
326(32.0) \\
15(1.5) \\
522(51.2) \\
422(41.4) \\
139(13.6) \\
142(13.9) \\
599(58.8) \\
295(28.9) \\
175(17.2) \\
50(4.9) \\
48(4.7) \\
40(3.9) \\
94(9.2)\end{array}$ & $\begin{array}{l}12 \mid(13.6) \\
4(0.5) \\
274(30.9) \\
11(1.2) \\
449(50.6) \\
339(38.2) \\
118(13.3) \\
131(14.8) \\
526(59.3) \\
267(30.1) \\
146(16.5) \\
38(4.3) \\
37(4.2) \\
28(3.2) \\
80(9.0)\end{array}$ & $\begin{array}{l}23(17.4) \\
0(0) \\
52(39.4) \\
4(3.0) \\
73(55.3) \\
83(62.9) \\
21(15.9) \\
11(8.3) \\
73(55.3) \\
28(21.2) \\
29(22.0) \\
12(9.1) \\
11(8.3) \\
12(9.1) \\
14(10.6)\end{array}$ & $\begin{array}{l}0.244 \\
1.000 \\
0.051 \\
0.228 \\
0.315 \\
<0.001 \\
0.416 \\
0.046 \\
0.384 \\
0.036 \\
0.117 \\
0.017 \\
0.035 \\
0.001 \\
0.557\end{array}$ \\
\hline \multicolumn{5}{|l|}{ Mechanical ventilation } \\
\hline $\begin{array}{l}\text { Invasive } \\
\text { Non-invasive }\end{array}$ & $\begin{array}{l}156(15.3) \\
118(11.6)\end{array}$ & $\begin{array}{l}138(15.6) \\
103(11.6)\end{array}$ & $\begin{array}{l}18(13.6) \\
15(11.4)\end{array}$ & $\begin{array}{l}0.567 \\
0.934\end{array}$ \\
\hline \multicolumn{5}{|l|}{ Eosinophils, \% } \\
\hline $\begin{array}{l}\text { Eosinophil }_{\text {initial }} \\
\text { Eosinophil max }_{\text {mea }} \\
\text { Eosinophil }\end{array}$ & $\begin{array}{l}0.5(0.1,1.5) \\
1.0(0.3,2.1) \\
0.5(0.2,1.4)\end{array}$ & $\begin{array}{l}0.6(0.1, I .6) \\
1.0(0.3,2.2) \\
0.6(0.2, I .4)\end{array}$ & $\begin{array}{l}0.2(0,0.875) \\
0.7(0.1,2.0) \\
0.3(0.1,0.8)\end{array}$ & $\begin{array}{l}<0.001 \\
0.001 \\
<0.001\end{array}$ \\
\hline Neutrophils, \% & $83.0(74.8,89.7)$ & $82.8(74.3,89.4)$ & $85.6(78.6,92.0)$ & 0.003 \\
\hline Lymphocytes, \% & $9.7(5.2,15.4)$ & $10.0(5.5,15.9)$ & $7.0(3.6,12.4)$ & $<0.001$ \\
\hline Systemic corticosteroid treatment & $844(82.8)$ & 735 (82.9) & $109(82.6)$ & 0.935 \\
\hline Antibacterial treatment & $909(89.2)$ & $786(88.6)$ & $123(93.2)$ & 0.115 \\
\hline
\end{tabular}

(Continued) 
Table I (Continued).

\begin{tabular}{|c|c|c|c|c|}
\hline Variables & Total $(n=1019)$ & Survivors $(n=887)$ & Non-Survivors $(n=132)$ & $p$ \\
\hline SAPS II & $37(29,45)$ & $35(29,43)$ & $47(39,59)$ & $<0.001$ \\
\hline SOFA score & $3(2,5)$ & $3(2,5)$ & $6(4,8)$ & $<0.001$ \\
\hline $\mathrm{PaO}_{2}, \mathrm{mmHg}$ & $87(69,|3|)$ & $87(69,127)$ & $87(69,138)$ & 0.652 \\
\hline $\mathrm{PaCO}_{2}, \mathrm{mmHg}$ & $56(46,72)$ & $56(47,72)$ & $55(41,73)$ & 0.143 \\
\hline $\mathrm{ph}$ & $7.34(7.27,7.39)$ & $7.34(7.27,7.39)$ & $7.32(7.24,7.39)$ & 0.207 \\
\hline Hospital LOS, day & $7.2(4.5,12.0)$ & $7.1(4.8,11.8)$ & $7.5(3.3,13.9)$ & 0.387 \\
\hline ICU LOS, day & $3.0(1.5,6.0)$ & $2.9(1.5,5.7)$ & 4.I $(1.8,9.3)$ & $<0.001$ \\
\hline
\end{tabular}

Notes: Eosinophil ${ }_{\text {initial }}$ was defined as the first value of blood eosinophil concentrations measured in the stage between 24 hours before admission and 24 hours after admission. Eosinophil max was defined as the maximum value during the hospitalization. Eosinophil mean was defined as the arithmetic mean of all values during hospitalization. Abbreviations: SOFA, sequential organ failure assessment; SAPS, simplified acute physiology score; LOS, length of stay.

Table 2 ORs of Eosinophil ${ }_{\text {initial }}$ for Outcomes

\begin{tabular}{|l|l|l|l|l|l|l|}
\hline \multirow{2}{*}{ Outcomes } & \multicolumn{2}{l|}{ Univariate Model } & \multicolumn{2}{l|}{ Multivariate Model I } & \multicolumn{2}{l|}{ Multivariate Model 2 } \\
\cline { 2 - 7 } & OR & $\mathbf{P}$ & OR & $\mathbf{P}$ & OR \\
\hline In-hospital mortality & $0.719(0.592-0.873)$ & 0.001 & $0.792(0.643-0.976)$ & 0.028 & $0.785(0.636-0.968)$ & 0.024 \\
In-ICU mortality & $0.746(0.603-0.923)$ & 0.007 & $0.812(0.645-1.022)$ & 0.076 & $0.807(0.64 I-1.016)$ & 0.068 \\
Hospital length of stay (>7days) & $0.849(0.78 I-0.924)$ & $<0.001$ & $0.847(0.772-0.930)$ & 0.001 & $0.854(0.778-0.939)$ & 0.001 \\
ICU length of stay (>3days) & $0.882(0.8 I 4-0.957)$ & 0.003 & $0.914(0.836-1.000)$ & 0.049 & $0.917(0.838-1.004)$ & 0.060 \\
\hline
\end{tabular}

Notes: Multivariate model I: adjusted for SAPS II score, cardiac arrhythmias, solid tumor, metastatic cancer, liver disease, neutrophils (\%), and mean VIF was I.09 for inhospital mortality. Multivariate model 2: adjusted for SOFA score, age, cardiac arrhythmias, solid tumor, metastatic cancer, liver disease, neutrophils (\%), and mean VIF was I. 10 for in-hospital mortality.

neutrophilic predominant were two common phenotypes among them. ${ }^{19,20}$ The patients with neutrophilic phenotype poorly responded to standard therapy; whereas the eosinophilic phenotype had a better response to corticosteroid treatment. $^{21,22}$ In our study, higher neutrophil concentrations and lower eosinophil concentrations were found in the nonsurvivors. However, the usage of systemic corticosteroid treatment was the same in the two groups. This meant that systemic corticosteroid treatment was poorly effective but brought adverse effects in the non-survivor group, which might contribute to the result. Besides, eosinophils had a relationship with bacterial infections. A study found that patients with potentially pathogenic microorganisms positive samples had significantly lower blood eosinophil counts at exacerbation compared to baseline, while no blood eosinophil change was observed with negative samples. ${ }^{23}$ Moreover, the role of eosinophils as antibacterial defenders in the host response was reported from an animal experiment. The results showed that mouse eosinophils could against Pseudomonas aeruginosa bacterial infection by releasing cationic secondary granule proteins. ${ }^{24}$ A retrospective study also found that low eosinophil counts were associated with high bacterial infection. ${ }^{11}$ All of these suggested that low eosinophil counts seemed to have a relationship with more serious infections, which might cause worse outcomes.

The values of $2 \%$ or $4 \%$ were always used in other studies $^{3,4,25-27}$ aimed at COPD patients as thresholds of blood eosinophil concentrations. Although these thresholds were widely used and had been proved that there were some differences in the treatment and outcomes in populations stratified by them, some of these thresholds were adopted from studies of asthma. ${ }^{28}$ Thus, whether they were the optimal threshold for COPD was unconfirmed. In our study, the median of initial blood eosinophil concentrations was $0.5 \%$ that was lower than other studies $^{9,29,30}$ aimed at AECOPD. The possible reason for this phenomenon was that these studies were aimed at AECOPD patients in the general wards, whereas our study was aimed at severe patients who had been in the 


\section{In-hospital mortality}

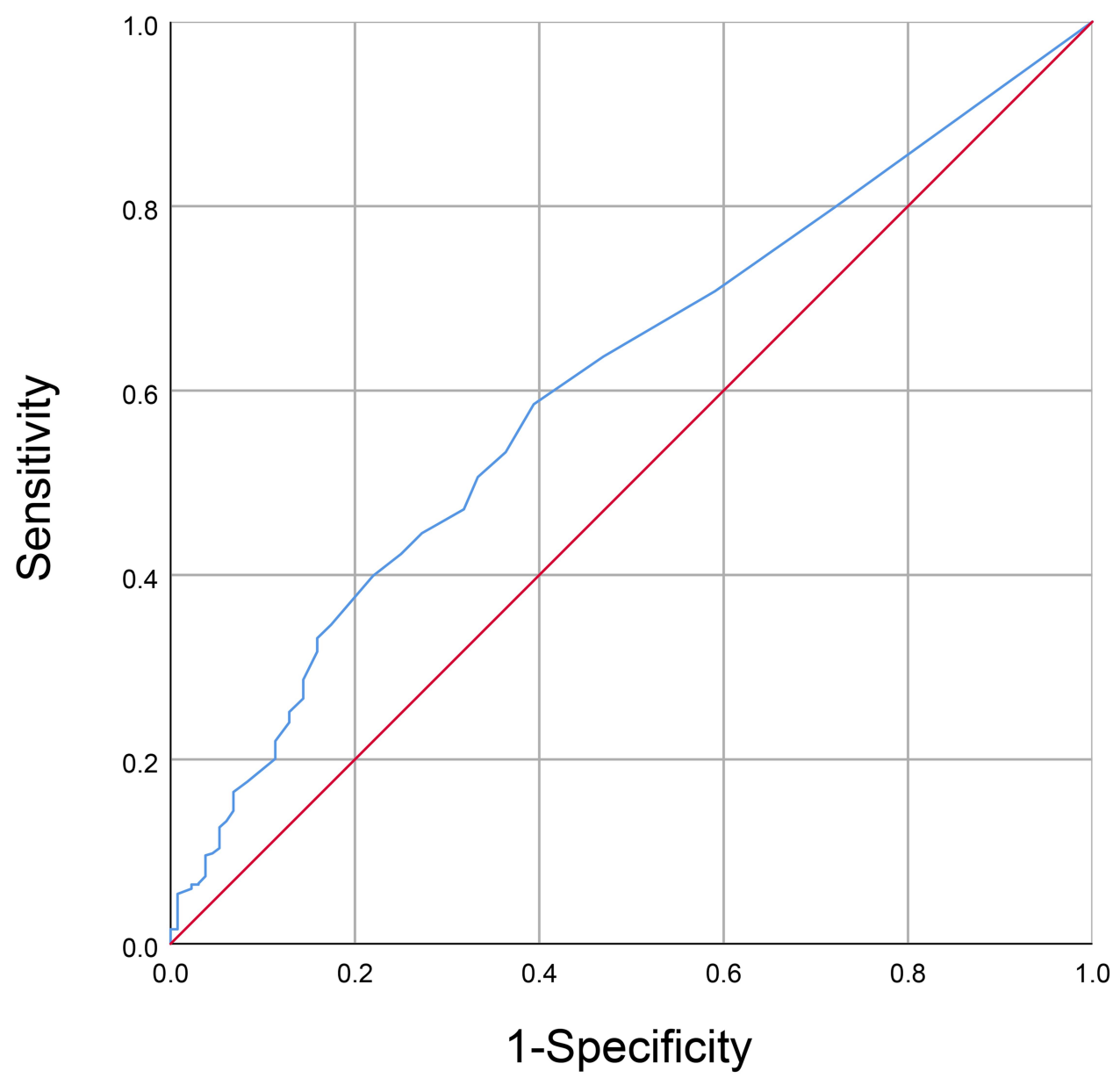

Figure 2 Receiver operating characteristic (ROC) curve for the prediction of in-hospital mortality in critically ill patients with AECOPD by eosinophil concentrations.

ICU. This also indirectly suggested that lower eosinophil seemed to be associated with a more severe condition. Additionally, the thresholds worked out from our study were $0.35 \%$, which was much lower than $2 \%$ or $4 \%$. We could not know the situation of the patients not included in our study due to the limited number of studies in critically ill patients with AECOPD. Hence, whether this threshold could be extended to the clinic remained to be confirmed. However, this could reflect that the conventional thresholds of $2 \%$ or $4 \%$ might not be suitable for severe patients, and further prospective studies with larger sample sizes were needed.

The advantages of this study were relatively considerable sample size and a new threshold proposed for critically ill patients with AECOPD, but it also had some limitations: First, only blood eosinophil concentrations were considered in this study. The blood eosinophil counts were not discussed because of hugely lacking the numeric value of them in the MIMIC-III database. The study will be more complete if blood eosinophil counts were considered together. Moreover, some other conditions also affect eosinophil concentrations, such as some allergic diseases and hematological diseases. Additionally, patients may have been treated with corticosteroids before admission, which might affect the value of eosinophils. We could not eliminate these whole factors, which may cause some bias. Future research could be devoted to exploring a more optimal threshold of blood eosinophil in critically ill patients with AECOPD.

\section{Conclusion}

Increased blood eosinophils were associated with decreased in-hospital mortality and shorten hospital length of stay in critically ill patients with acute exacerbation of chronic obstructive pulmonary disease. A discriminatory 
eosinophil threshold of $0.35 \%$ for mortality was found, but further studies were needed to verify it.

\section{Abbreviations}

COPD, chronic obstructive pulmonary disease; AECOPD, acute exacerbation of chronic obstructive pulmonary disease; MIMIC-III, Medical Information Mart for Intensive Care III; LOS, length of stay; ROC, receiver operating characteristic; SAPS, simplified acute physiology score; SOFA, sequential organ failure assessment.

\section{Ethics Approval and Consent to Participate}

This study was approved by ethics committee of the First Affiliated Hospital of Zhejiang Chinese Medical University [2020-KL-154-01]. Because the database does not contain protected health information, a waiver of the requirement for informed consent was included in the IRB approval.

\section{Funding}

This study was supported by National Key R\&D Program of China (2018YFC2002500).

\section{Disclosure}

The authors report no conflicts of interest in this work.

\section{References}

1. Hastie AT, Martinez FJ, Curtis JL, et al. Association of sputum and blood eosinophil concentrations with clinical measures of COPD severity: an analysis of the SPIROMICS cohort. Lancet Respir Med. 2017;5(12):956-967. doi:10.1016/S2213-2600(17)30432-0

2. Kerkhof M, Sonnappa S, Postma DS, et al. Blood eosinophil count and exacerbation risk in patients with COPD. Eur Respir J. 2017;50:1.

3. Vedel-Krogh S, Nielsen SF, Lange P, Vestbo J, Nordestgaard BG. Blood eosinophils and exacerbations in chronic obstructive pulmonary disease. the copenhagen general population study. Am J Respir Crit Care Med. 2016;193(9):965-974. doi:10.1164/rccm.201509$18690 \mathrm{OC}$

4. Pascoe S, Locantore N, Dransfield MT, Barnes NC, Pavord ID. Blood eosinophil counts, exacerbations, and response to the addition of inhaled fluticasone furoate to vilanterol in patients with chronic obstructive pulmonary disease: a secondary analysis of data from two parallel randomised controlled trials. Lancet Respir Med. 2015;3 (6):435-442. doi:10.1016/S2213-2600(15)00106-X

5. Pavord ID, Lettis S, Locantore N, et al. Blood eosinophils and inhaled corticosteroid/long-acting $\beta-2$ agonist efficacy in COPD. Thorax. 2016;71(2):118-125. doi:10.1136/thoraxjnl-2015-207021

6. Suissa S, Dell'Aniello S, Ernst P. Comparative effectiveness of LABA-ICS versus LAMA as initial treatment in COPD targeted by blood eosinophils: a population-based cohort study. Lancet Respir Med. 2018;6(11):855-862. doi:10.1016/S2213-2600(18)30368-0
7. Cheng SL. Blood eosinophils and inhaled corticosteroids in patients with COPD: systematic review and meta-analysis. Int J Chron Obstruct Pulmon Dis. 2018;13:2775-2784. doi:10.2147/COPD. S175017

8. Wu CW, Lan CC, Hsieh PC, Tzeng IS, Wu YK. Role of peripheral eosinophilia in acute exacerbation of chronic obstructive pulmonary disease. World j Clin Cases. 2020;8(13):2727-2737. doi:10.12998/ wjcc.v8.i13.2727

9. Wu HX, Zhuo KQ, Cheng DY. Peripheral blood eosinophil as a biomarker in outcomes of acute exacerbation of chronic obstructive pulmonary disease. Int $J$ Chron Obstruct Pulmon Dis. 2019;14:3003-3015. doi:10.2147/COPD.S226783

10. Prins HJ, Duijkers R, Lutter R, et al. Blood eosinophilia as a marker of early and late treatment failure in severe acute exacerbations of COPD. Respir Med. 2017;131:118-124. doi:10.1016/j.rmed.2017.07.064

11. Choi J, Oh JY, Lee YS, et al. The association between blood eosinophil percent and bacterial infection in acute exacerbation of chronic obstructive pulmonary disease. Int J Chron Obstruct Pulmon Dis. 2019;14:953-959. doi:10.2147/COPD.S197361

12. Sivapalan P, Lapperre TS, Janner J, et al. Eosinophil-guided corticosteroid therapy in patients admitted to hospital with COPD exacerbation (CORTICO-COP): a multicentre, randomised, controlled, open-label, non-inferiority trial. Lancet Respir Med. 2019;7 (8):699-709. doi:10.1016/S2213-2600(19)30176-6

13. MIMIC-III, a freely accessible critical care database. Johnson AEW, Pollard TJ, Shen L. Scientific Data (2016). DOI: 10.1038/ sdata.2016.35. IEEE Transactions on Bio-Medical Engineering 64 1914-1923

14. Wedzicha JA, Seemungal TA. COPD exacerbations: defining their cause and prevention. Lancet. 2007;370(9589):786-796. doi:10.1016/ S0140-6736(07)61382-8

15. Holland M, Alkhalil M, Chandromouli S, Janjua A, Babores M. Eosinopenia as a marker of mortality and length of stay in patients admitted with exacerbations of chronic obstructive pulmonary disease. Respirology. 2010;15(1):165-167. doi:10.1111/j.14401843.2009.01651.x

16. Rahimi-Rad MH, Asgari B, Hosseinzadeh N, Eishi A. Eosinopenia as a marker of outcome in acute exacerbations of chronic obstructive pulmonary disease. Maedica. 2015;10(1):10-13.

17. Saltürk C, Karakurt Z, Adiguzel N, et al. Does eosinophilic COPD exacerbation have a better patient outcome than non-eosinophilic in the intensive care unit? Int $J$ Chron Obstruct Pulmon Dis. 2015;10:1837-1846. doi:10.2147/COPD.S88058

18. Zhou A, Zhou Z, Zhao Y, Chen P. The recent advances of phenotypes in acute exacerbations of COPD. Int J Chron Obstruct Pulmon Dis. 2017;12:1009-1018. doi:10.2147/COPD.S128604

19. Gao P, Zhang J, He X, Hao Y, Wang K, Gibson PG. Sputum inflammatory cell-based classification of patients with acute exacerbation of chronic obstructive pulmonary disease. PLoS One. 2013;8 (5):e57678.

20. Barnes PJ. Inflammatory mechanisms in patients with chronic obstructive pulmonary disease. J Allergy Clin Immunol. 2016;138 (1):16-27. doi:10.1016/j.jaci.2016.05.011

21. Toraldo DM, Conte L. Influence of the lung microbiota dysbiosis in chronic obstructive pulmonary disease exacerbations: the controversial use of corticosteroid and antibiotic treatments and the role of eosinophils as a disease marker. J Clin Med Res. 2019;11 (10):667-675. doi:10.14740/jocmr3875

22. Bafadhel M, McKenna S, Terry S, et al. Blood eosinophils to direct corticosteroid treatment of exacerbations of chronic obstructive pulmonary disease: a randomized placebo-controlled trial. Am J Respir Crit Care Med. 2012;186(1):48-55. doi:10.1164/rccm.201108$1553 \mathrm{OC}$

23. Kolsum U, Donaldson GC, Singh R, et al. Blood and sputum eosinophils in COPD; relationship with bacterial load. Respir Res. 2017;18(1):88. doi:10.1186/s12931-017-0570-5 
24. Linch SN, Kelly AM, Danielson ET, Pero R, Lee JJ, Gold JA. Mouse eosinophils possess potent antibacterial properties in vivo. Infect Immun. 2009;77(11):4976-4982. doi:10.1128/IAI.00306-09

25. Vedel-Krogh S, Nordestgaard BG, Lange P, Vestbo J, Nielsen SF. Blood eosinophil count and risk of pneumonia hospitalisations in individuals with COPD. Eur Respir J. 2018;51:5. doi:10.1183/ 13993003.00120-2018

26. Barnes NC, Sharma R, Lettis S, Calverley PM. Blood eosinophils as a marker of response to inhaled corticosteroids in COPD. Eur Respir J. 2016;47(5):1374-1382. doi:10.1183/13993003.01370-2015

27. Watz H, Tetzlaff K, Wouters EF, et al. Blood eosinophil count and exacerbations in severe chronic obstructive pulmonary disease after withdrawal of inhaled corticosteroids: a post-hoc analysis of the WISDOM trial. Lancet Respir Med. 2016;4(5):390-398. doi:10.1016/S2213-2600(16)00100-4
28. Tashkin DP, Wechsler ME. Role of eosinophils in airway inflammation of chronic obstructive pulmonary disease. Int J Chron Obstruct Pulmon Dis. 2018;13:335-349. doi:10.2147/COPD.S152291

29. Gao J, Zhang M, Zhou L, et al. Correlation between fractional exhaled nitric oxide and sputum eosinophilia in exacerbations of COPD. Int J Chron Obstruct Pulmon Dis. 2017;12:1287-1293. doi:10.2147/COPD.S134998

30. Ko FWS, Chan KP, Ngai J, et al. Blood eosinophil count as a predictor of hospital length of stay in COPD exacerbations. Respirology. 2020;25(3):259-266. doi:10.1111/resp.13660

\section{Publish your work in this journal}

The International Journal of COPD is an international, peer-reviewed journal of therapeutics and pharmacology focusing on concise rapid reporting of clinical studies and reviews in COPD. Special focus is given to the pathophysiological processes underlying the disease, intervention programs, patient focused education, and self management protocols. This journal is indexed on PubMed Central, MedLine and CAS. The manuscript management system is completely online and includes a very quick and fair peer-review system, which is all easy to use. Visit http://www.dovepress.com/testimonials.php to read real quotes from published authors. 